\title{
The gap in the research on life sciences between the underdeveloped and developed countries and the help of the science of biometry in achieving the collaboration required
}

\begin{abstract}
Biometry is the application of mathematical and statistical methods in order to reach valid interpretations of biological observations and the right conclusions when evaluating biological experiments. It offers the tools for obtaining valid answers to important research questions which can assist in identifying the optimal agricultural approaches for achieving the highest levels of production in different climates and environments. Answering such questions has the potential to guide the development of rural and under-developed areas, ensure food security, promote local growth, reduce poverty and migration, and create jobs through the use of local natural resources and intensification of sustainable agricultural production and processing.

However, this study shows the scarcity of methodologically robust agricultural and environmental research according to the biometric principles in such under-developed areas, where one can argue is most needed for economic growth and poverty reduction. The main aim of IBS is to promote the development and application of biometric methods. There is a need to focus such work on areas which are under-represented in the biological research field. Such an approach will help towards developing adaptive agricultural techniques, building capacity, maximizing the global agricultural potential, and efficiently using domestic natural resources. It may also assist towards solving some of the major global challenges associated with increasing urbanization, human migration, and climate change.
\end{abstract}

Volume 7 Issue 2 - 2018

\author{
Stergios Tzortzios \\ Imperial College/London University, Greece
}

Correspondence: Stergios Tzortzios, Imperial College/London University), f. Professor-University of Thessay,Volos-Greece, Email stzortz@uth.gr, stzortzios56@gmail.com

Received: December 19, 2017 | Published: April 03, 2018

\section{Introduction}

Starting from the meaning of each of the words in the title of the speech we should try to understand that we- as members of the International Biometric Society, which means as the main servants of the science of biometry- are obliged to review IBS's effectiveness today in applying biometry to biological research, to make it the basic tool for the improvement of biological research globally. It means that we must survey the data related to the biological research done in each one of all the countries in the world, where we'll realize that:

i. There is a remarkable gap between the relative number of publications presented by the researchers of the developed, the developing and under-developed countries (SJR). ${ }^{1}$

ii. Even in the most developed countries there is not the best possible collaboration between statisticians and researchers in the fields of biological, agricultural and environmental sciences. ${ }^{2}$

It is a general admission that the current system of teaching biometry is not of the effectiveness expected-especially in developing countries. Collaboration between researchers of the various countries in biological research is lower than should be expected. It is very urgent the call of the World's Organizations (e.g. FAO) for the proper actions of the scientific societies to make intensive efforts for the best possible research in the fields of environment-food production and supply-human health. It is biometry's duty to help the biological researchers in organizing their research from the first step of researchexperimental design, to data collection and its proper organization, data analysis and interpretation and the presentation and publication of results.

The current situation shows the importance of the necessary collaboration among and between biometricians and researchers of the different scientific sectors in order to approach the research goals to the best and the most fruitful result. This is the subject of this paper - to emphasize the importance of this very serious matter and to make some proposals to IBS on the reorganization of its services and activities to best effect- based on the real meaning of its bylaws. The Sciences have been created with their main task to create knowledge aiming to the improvement of the peoples' (health and welfare) standards of living. The politicians and the Governments require the knowledge derived from the sciences in order to make the proper decisions for the best possible welfare to their people. Biometry's task -as a science- is to offer knowledge from its work in "measuring life" (as the word biometry is a Greek double word coming from the words "bio" which means life and "metro" which means measure). According to the International Biometric Society's bylaws the task of the Society (and of course its members) is the generation of knowledge in statistical applications in biological research, e.g. in the fields of the sciences of agriculture, medicine and environment. It is the great privilege of IBS that makes it to be a very important and well respected organization by society, expecting of course to see the 
proper contribution required for the improvement of research in the above-named particular scientific sectors. The effect of these three sciences in the people's life is of the greatest importance. The chain of the influence of the environment to the form and quality of the agricultural production and the effect of both of them to the people's health and welfare consists in an integrated system that is the basic substance of the human life. Therefore this defines the importance of biometry as the responsible science from which the people require its proper contribution to their lives.

\section{What is the today's status}

Questions arise whether the today's performance of the IBS organization as an International Society offers the best possible contribution to the biological research globally. But the various calls for help in research collaboration from all the developing countries don't support this. On the contrary, urgent ascertainments on the need for changes in the methodology of teaching biometry as applied research methods and statistics in scientific sectors - and on the collaboration in the practice, are quite often outputs in IBS conferences, especially in those of the IBS Regions and Groups of the developing countries. In the following an attempt is presented to get an idea about the research done in the last years in all the countries in the three sciences- environment, agriculture, health-medicine, through their publications in the period from 1996 to 2013 and make the comparisons between them (using SJR). ${ }^{1}$

\section{A brief presentation of the publications presented in journals for all the countries in the world}

\section{(All the studies refer to the period 1996-20I3)}

The documents of all the countries presented in journals: In the subject area of "Agricultural and Biological Sciences-miscellaneous". The number of publications range from 85.076 (for USA) down to 1 or 2 and up to 50 in the 110 developing countries (out of 220 in total), with the respective number of Citations per document ranging from 29 to 0 or 1 up to 5 , and the H-Index from 287 to 0 or 1 up to 10. In the subject area of "Environmental Sciences Miscellaneous" the number of publications range from 54000 (for USA) and around 10000-20000 for five more developed countries down to 1- 10 in 140 developing countries (out of 214 in total), with the respective citations per document from some thousands or hundreds for the developed countries down to 0 or single digit numbers for developing countries. In the subject area of "Health Professions Miscellaneous" the number of publications range from some hundreds to the most developed 23 countries down to $0-50$ for the rest of the 126 countries presented No comments for the citations.

\section{A comparison between the continents for their published research}

In the field of agricultural research: Comparison for their documents published (Figure 1A). 1B).

Comparison for the H-index of their documents published (Figure

Comparison for their collaboration in their documents published (in percentage of documents with more than one country) (Figure 1C).

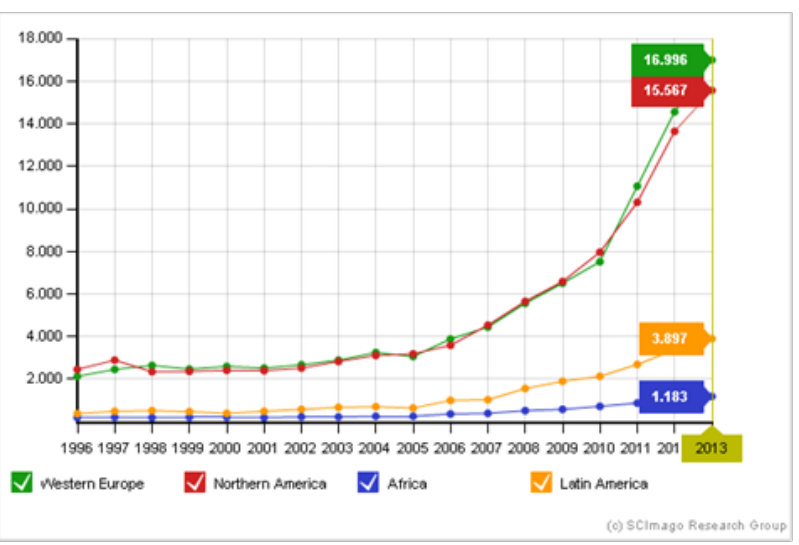

Figure I (A) Comparison W Europe-N America-Africa-Latin America for Documents

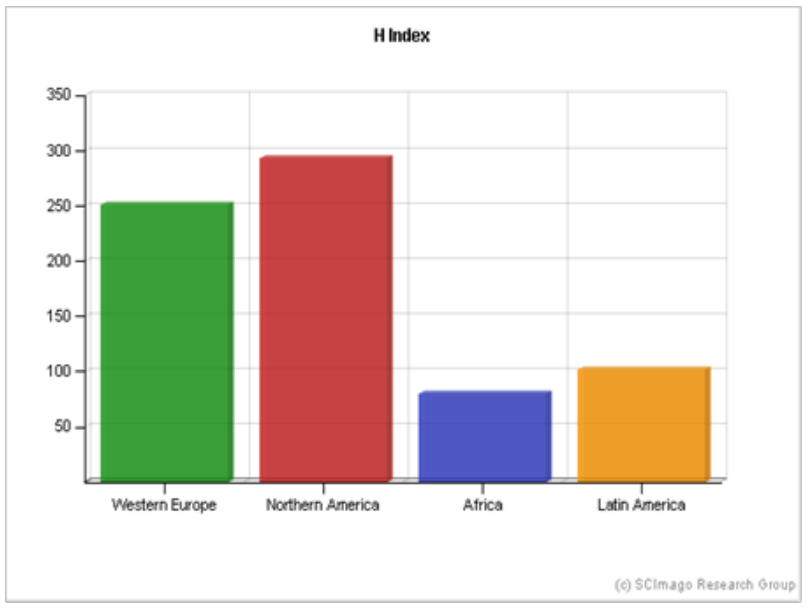

Figure I (B) Comparison W Europe-N America-Africa-Latin America for $\mathrm{H}$-Index

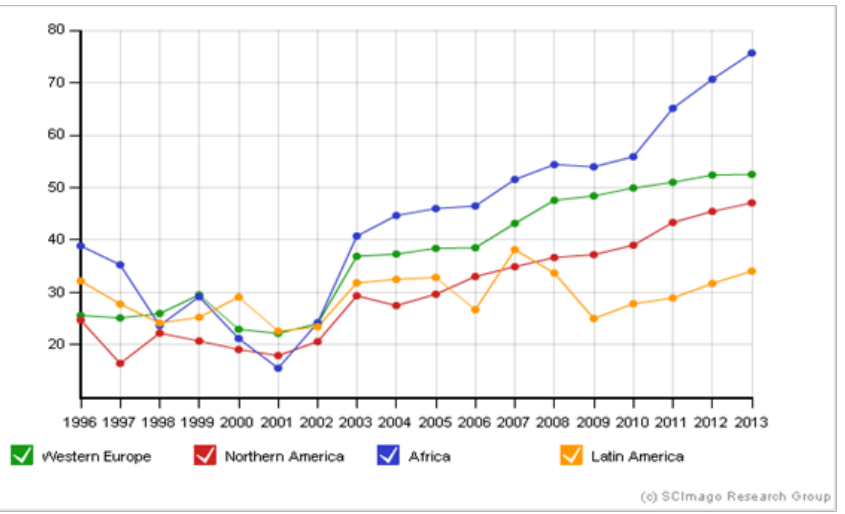

Figure I (C) Comparison W Europe-N America-Africa-Latin America for International collaboration.

In the field of environmental research, Comparison for their documents published (Figure 2A). 2B). 
Comparison for their collaboration in their documents published (in percentage of documents with more than one country) (Figure 2C).

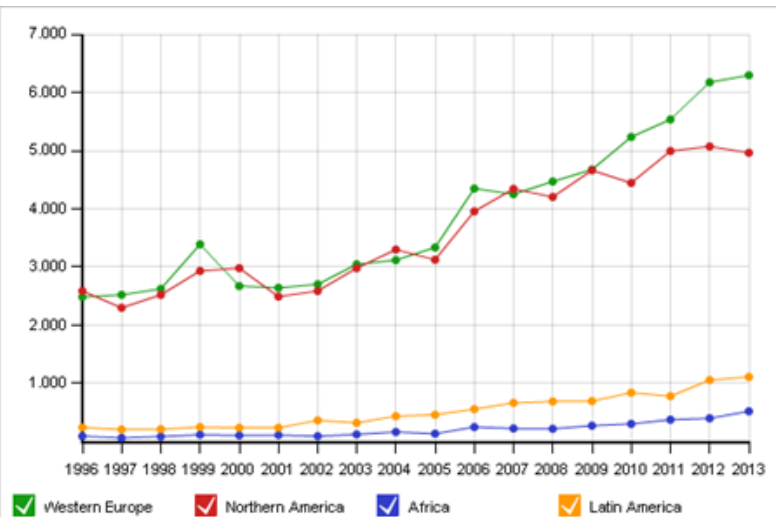

Figure 2 (A) Comparison W Europe-N America-Africa-Latin America for Documents

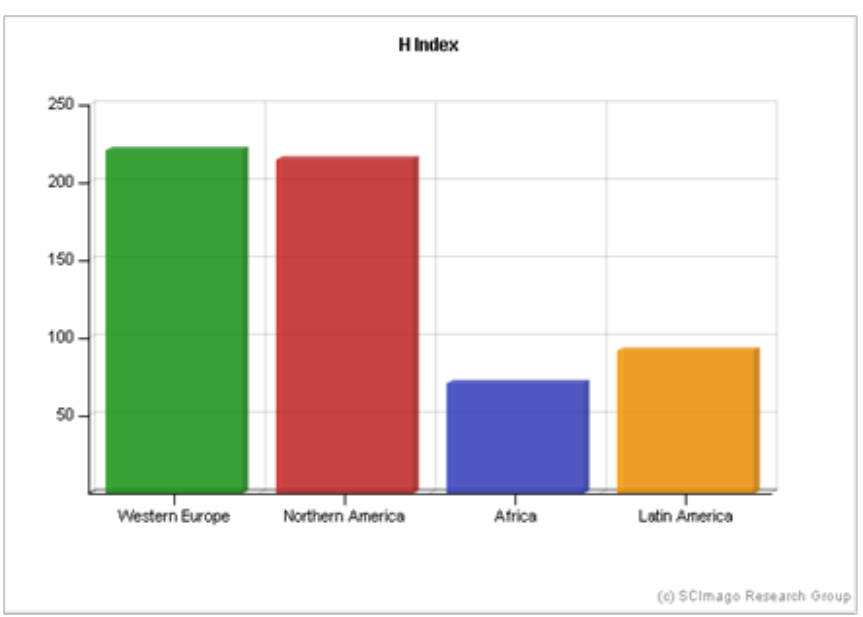

Figure 2 (B) Comparison W Europe-N America-Africa-Latin America for H-Index.

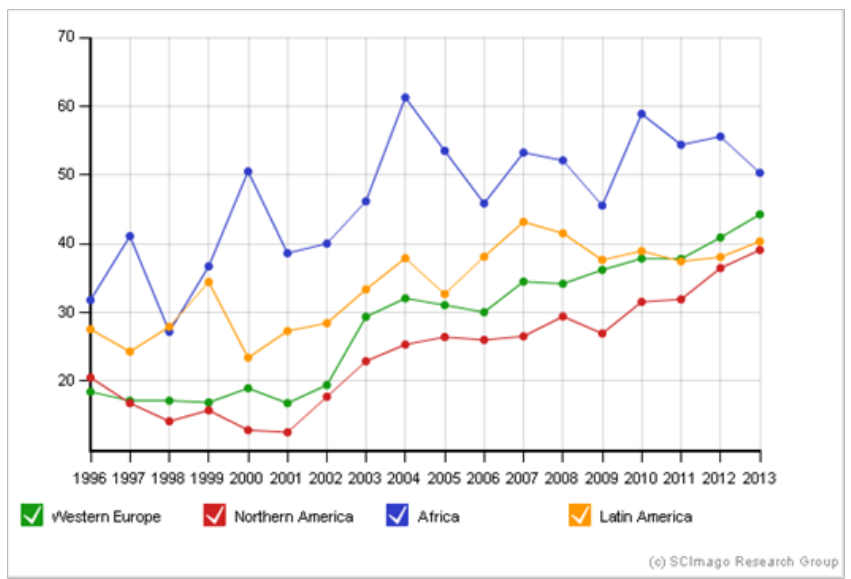

Figure 2 (C) Comparison W Europe-N America-Africa-Latin America for International collaboration

In the field of Health research, Comparison for their documents published (Figure 3A).

Comparison for the $\mathrm{H}$-index of their documents published (Figure
3B)

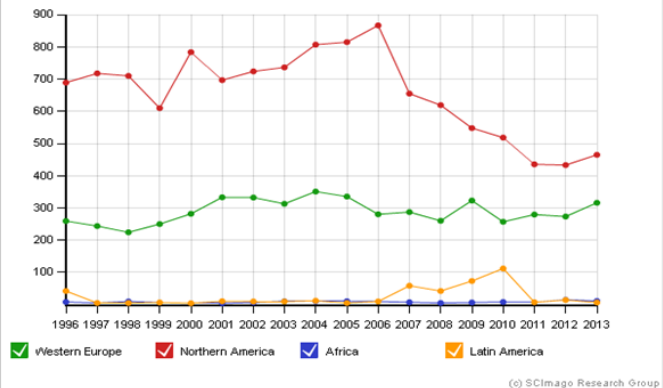

Figure 3 (A) Comparison W Europe-N America-Africa-Latin America for published Documents.

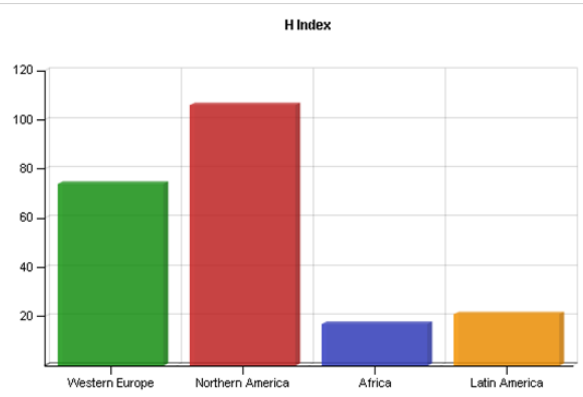

Figure 3 (B) Comparison W Europe-N America-Africa-Latin America for $\mathrm{H}$-Index

Comparison for their collaboration in their documents published (in percentage of documents with more than one country) (Figure 3C) (Figure 4).

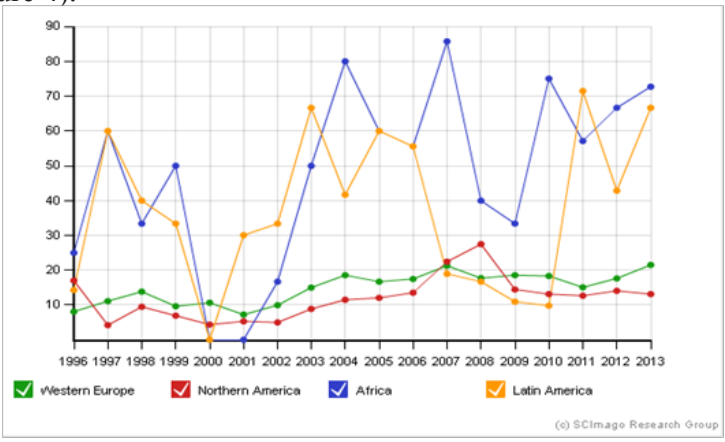

Figure 3 (C) Comparison W Europe-N America-Africa-Latin America for International collaboration.

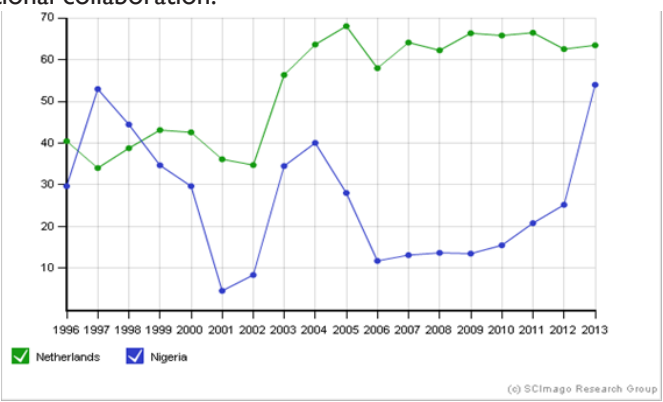

Figure 4 A Comparison between Netherlands-Nigeria for their International Collaboration (in percentage of documents with more than one country). 
The conclusion of the figures presented: The above figures show the great difference between the continents, and more particularly between the developed and developing countries in the number of publications and their H-Index which means the quantity and the quality of the research. However, it can be emphasized that there is increasing interest in the developing world in collaboration with colleagues from other counties in order to increase the quantity and quality of their biological research.

\section{A search of the aspects presented in various biometric conferences and meeting}

From a very extensive search undertaken through many biometric conferences and meetings organized by various IBS regions mainly in the developing countries it was discovered what is very well presented in the following reports:

a. In the African conference of 1999 in Sudan in her speech Riley presented on "Strengthening biometry and statistics in agricultural research: Review of the CTA study". It referred to a study done between 1995 and 1998 by the Technical Centre for Agricultural and Rural Cooperation (CTA) and Rothamsted Experimental Station to examine the reasons underpinning the problems encountered by scientists in African, Caribbean and Pacific countries (ACP) in incorporating good biometric quality in their research work.

b. In order to explore more deeply the reasons why scientists may not have good biometric skills or support, a case study was made of a national agricultural research service in an African country.

c. This three-week study involved an assessment of the position in the organization of the biometrics personnel, a study of the efficiency of the services provided by them to the scientists and recommendations for future developments of the group.

\section{Conclusion}

i. Together with the biometrician it was proposed a strategy to provide:

ii. Improvements in the skills of the biometrician, involving short attachments to biometricians in European universities,

iii. Training courses provided by IARC biometricians (from which the NARI biometrician would gain knowledge) and

iv. The identification of key scientific personnel to go to the IARC centers for training in specific biometric topics. In this way, skilled biometric resource persons would be available in the scientific departments, alleviating pressure from the NARI biometrician who could concentrate on the provision of more advanced biometric advice.

Whilst all institutes are different, there are common factors underlying the lack of progress in improving biometric skills. The first of these is the need to upgrade regularly with new techniques. Whilst training attachments are fruitful, they are expensive and it is becoming more cost effective with increased access to the Internet to find material on these techniques at a range of websites. The second factor was to be aware of the changes in research directions as globalization and environmental concerns become more important, and to have the skills to manage these changes by updating one's biometric knowledge with the most appropriate skills to support the new directions. The desire to learn every new technique should not be encouraged, but to develop expertise in key methods appropriate for the clients' priority research, which will develop the biometrician's own confidence and encourage others' confidence in him/her.

\section{As a general conclusion}

It is better to manage well a little knowledge than to mismanage a lot of knowledge.

In another interesting report on Africa's research: (by Muza Gondwe "Malawi, a small poor country but with a significant scientific publication record", July10/ by BMJ) it was emphatically reported:

a. The importance of the collaboration between the researchers by presenting a comparison between two African countries -a small one as is Malawi and a much bigger as is Nigeria in their research results.

b. The report says, ".... other countries with limited resources are making notable and effective contributions of a high standard. Other analyses show that Malawi, with one-tenth the annual research output of Nigeria, produces research of a quality that exceeds the world average benchmark while Nigeria hovers around half that impact level."

c. There is much to be gained from these collaborations, for example access to modern facilities, technical expertise, and opportunities to publish in reputable journals.

A Survey and evaluation of biometric approaches in the field of agriculture in Greece (in 2002-2003 by the Lab. of Biometry/ University of Thessaly, Tzortzios ${ }^{5,6}$ ) presented the following:

A first remarkable conclusion was the notable difference between the various basic sectors of agriculture in broad sense (e.g. plant science and production, animal science and production, food technology, engineering and natural recourses, forestry, agricultural economics and management) on the following main biometrical approaches:

i. Ways of Data Management, Collection, Organization and Manipulation;

ii. Methods of Statistical Analysis-processing;

iii. The Experimental designs used;

iv. The computer equipment-Software used. It was somewhat unsurprising due to the natural differences in their research subject and material from basic points of view; but at the same time it could be a very helpful tool to all of them mutually in case each one of them knew the work done by the others and they could find ways of exchanging their knowledge and experience.

It is probably the duty of the Labs of Biometry in each research centre to help the biological scientists by offering their collaboration in all the steps of their research. Various Prospects were expressed by the ever memorable Professor Marvin Zelen. ${ }^{7}$ Since 1983, Marvin Zelen ${ }^{7}$ in his Invited speech in the IBS Conference (Biometrics (C) 1983 International Biometric Society) of the title "Biostatistical Science as a Discipline: A Look into the Future" noted.

"The field of biostatistics is enjoying unparalleled developments. Never before have had members of our profession been in such 
demand. Current applications are significantly influencing the direction of research in statistical methodology. It is not clear whether there is a discipline which can be termed 'biostatistics', but we are part of the emergence of a discipline which is termed 'biostatistical science'.

a. It refers to the applications of statistics, probability, computing and mathematics to the life sciences, with the goal of advancing our knowledge of a subject-matter field in this area. This paper discusses the role of computing, some aspects of training, and future directions of biostatistical science.

b. A special role is envisioned for the Biometric Society to be more active in problems associated with developing countries.

c. In another keynote talk of the title "Biostatisticians, Biostatistical Science and the future" in EMR 2005 conference Marvin Zelen ${ }^{8}$ noted:

d. "I prefer to use the term Statistical Science to describe the practice of Statistics. By Statistical Science, I mean the application of statistics, probability, mathematics and computing to advance our understanding of a subject matter field. I refer to the practitioners of Statistical Science as Statistical Scientists - not Statisticians. The terms statistics and statisticians have an ancestry when statistics was concerned with "political arithmetic".

When the main field of application is in the biomedical sciences or agronomy we may often describe this activity as Biostatistical Science and its practitioners as Biostatistical Scientists.

After all - what is that IBS can do: To assign to the Education Committee the work of the construction of a proper teaching programme - as a guide to the Schools, based on the most interesting biometrical practical applications to biological sciences according to the most important scientific interests now a days.

a. To organize more IBS conferences in the areas of the developing countries, e.g. Africa, South America.

b. To make suggestions to the IBS Regions to develop specific collaborations with researchers of the developing countries.

c. To decide the disposal of a special budget for postgraduate and postdoctoral biometric studies to make their research in the developing countries.

d. To make suggestions to the IBS Regions to accept in their conferences mainly papers referred to biometric applications in the three basic sectors of the IBS , e.g. medicine, agriculture, environment, (the pure statistical papers could be presented as posters or a few selected in a special session.)

e. To do the same suggestions to JABES to accept only or mainly applied biometrical papers for publication. f. To organize a Global Committee and Sub-committees for the yearly collection of the research done on each of the three basic sectors in order to announce the general conclusions to the proper International Organizations (and maybe to the respective Governments)

g. To create internet links with other Scientific Libraries of the Life Scientific Societies in order to be kept aware about their research interests and organize the relevant collaborations.

h. To construct the IBS site in a way so that most of the as above information can be straightforwardly available to and announced for all the researchers and all the interested World Organizations.

i. To maintain links with the IT scientific Societies e.g. BioIT, WFITA for their contribution to a better utilization of the multi-factorial projects information from the life sciences research globally.

\section{Acknowledgement}

None.

\section{Conflict of interest}

The author declares there is no conflict of interest

\section{References}

1. Scimago Journal \& Country Rank. USA: SJR; 2015.

2. Billard. The Roads Travelled: Our 50-Year Journey. Advances of Biometry-50 Years of the International Biometric Society; 1996.

3. J Riley. Strengthening biometry and statistics in agricultural research Germany: Proceeding of a CTA/University of Hohenheim workshop; 1996.

4. Muza Gondwe. Malawi, a small poor country but with a significant scientific publication record, interesting report on Africa's research. 2010.

5. Tzortzios S. A survey of the biometric methodologies used in the agricultural research institutes in Greece and in Slovenia. Contractor of the Bilateral Programme Greece-Slovena-GSRT; 2003.

6. Tzortzios S. Invited speech: A study of the Biometric and Computer Applications in agricultural education and research-A Greek case study. XIX ${ }^{\text {th }}$ Summer School of Biometrics, organized by the Board of Biometrics of the Czech Academy of Agricultural Science, LedniceCzeck Rep; 2010.

7. Marvin Zelen. Invited speech in the IBS Conference of the title "Biostatistical Science as a Discipline: A Look into the Future". 1983.

8. Marvin Zelen. A keynote talk of the title"Biostatisticians, Biostatistical Science and the future" in EMR2005 conference. 2005. 